\title{
The design of e-learning applications by considering aspects of the user's personality based on students take courses in human- computer interaction
}

\author{
Supangat ${ }^{\mathrm{a},}$, Francisca Haryati Chandar ${ }^{\mathrm{b}}$, and Agus Hermanto ${ }^{\mathrm{c}}$ \\ ${ }^{a}$ Universitas 17 Agustus 1945, Jl. Semolowaru 45, Surabaya, Indonesia \\ bSekolah Tinggi Teknik Surabaya, Surabaya, Indonesia \\ bUniversitas 17 Agustus 1945, J1. Semolowaru 45, Surabaya, Indonesia.
}

\begin{abstract}
The success of an E-Learning is determined from two elemen such as instructional design and user interface design. This study focuses on user interface design. To get a user interface design that suits the personality of students, with carried out research using data mining in e-learning participants. This study uses association rule mining to user design interface of an e-learning application. From the results of the process of training and testing of the 344 (three hundred and forthty-four) dataset consisting of 233 datasets training and 121 datasets testing, introverted personality types, shows that there are two combinations that come from these two processes when counting frequent itemset, namely: \{ Times New Roman, Blue, White $\}$ and $\{$ White, Black, Calibri\}, whereas personality types extrovert, no combination of dominant favored by this type, and the results are identical to the results of the process of training data, with a choice of preferred color is Blue as foreground and background colors are White. Both of these colors appear in the results of the process of training and testing datasets, with selected font is Arial.
\end{abstract}

\section{Introduction}

Information technology and advanced rapidly in the last decade, especially the rapid proliferation in the use of the internet and the world wide web is changing the way of life, work, communicate, and human learning. Several studies have shown that a variety of technologies, interactive distance learning cause positive changes in teaching and learning process when compared to the previous distance learning system.

Distance learning is interactive in the current era is the E-learning. E-learning in its broadest sense to encompass learning is done in electronic media (internet) either formally or informally. E-learning refers to the use of Internet technology to transmit a series of solutions that improve the knowledge and skills. It's important to understand how this new technology can affect learning when used by different types of learners.

The visual part of the program E-learning is the appearance of colors, text size, layout, look and feel of the menu or function of the parameters in affecting user interaction with the learning media. As the researchers, the goal in designing and selecting colors, navigation, and buttons have to anticipate what learners need to do and how they will do it. In addition, it should be considered is the use of the method in designing the interface according to the personality of E-learning. So the E-learning is not just learning media alone but can be overcome and help participants E-learning in the plurality of their personality.
To analyze the design of the user interface as it suits the personality of students will require a study using data mining methods to explore the personality of E-learning with user interface design. Researchers used Association rule mining algorithms using a priori to explore each students's personality relevance with user interface design of an E-learning which already exist. From the findings of existing rules which were analyzed by the researchers then used a reference in making e-learning that will be tested on the same students and analyzed the results in order to determine the level of student satisfaction in the use of E-Learning and increase students' ability in understanding the content of its E- Learning.

\section{Literature Review}

More than twenty years ago, Perraton says that "distance education has been successful without theory" (Perraton, 1981). The same thing can be said today of E-Learning, though whether or not it has' succeeded very well may not be so accurate. However, of the various articles that have been published, indicate that institutional investment in practice and uptake of Web-based educational tools for the past decade has proven practice E-Learning has reached a momentum that will make it a central part of future education. However, most of the literature on ELearning is a practice-based and usually presented in a descriptive format.

\footnotetext{
* Corresponding author: supangat@untag-sby.ac.id
} 
With the development of online learning terms, these terms provide an overview of education that occurs only through the Web, ie, does not consist of physical learning materials issued to learners or face to face. The essential pure of online learning to use the tools E-Learning in distance education mode via the Web as the only medium for all students' and contacts.

While the term mixed mode based learning resources, in turn, explains the educational approach that incorporates a face-to-face and distance education between the instructor or teacher to meet with students (either in person or through technology) and material resources basic content and learning activities available for learners. Learning Management System (LMS) is a learning management system that can be used as a platform for online courses or components built using a particular program.

The interface is an interactive E-Learning, there are two types, namely interactivity indicative and simulative. Interactivity indicative denoted by the use of rollover buttons and navigation. Clicking a button to start an animation or change the page is indicative interactivity. While the simulative interactivity is interactivity that allows students to learn from their own choices in a way that provides some form of feedback. The ability to choose between different Web pages is indicative interactivity; the ability to fly a virtual plane in a realistic virtual environment is simulative interactivity.

The next thing to note is to make sure the learning that occurs through e-learning programs, should be a priority in designing instruction for e-learning itself. Related to the above, that the theory of constructivism learning, which focuses on the construction of knowledge based on experience of previous participants, is suitable to be applied to e-learning because of the certainty of the learning process among students (Harman \& Koohang, 2007; Hung \& Nichani, 2001; Hung, 2001). The author of this study was used associate rule mining method that is used to categorize participants of E-Learning and getting relations elements in doing interface design in accordance with certain personality group as a participant E-Learning.

As has been explained that the associate rule mining is used in this research will discover certain patterns that associate the data with other data. To search for association rule from a data set, the first step to do is find frequent itemset first. A frequent itemset is a set of items that frequently appear simultaneously. After all patterns of a frequent itemset are found, then search for the associative rules or rules of relevance are eligible who have been determined (Arockiam \& Selvaraj, 2013; Fatahi, et al., 2009).

E-learning is a relatively new discipline to grow in the field of education. Advances in technology and the information age is able to change the pedagogy and the way we learn. Many researchers have shown that ELearning is one tool that can outperform traditional learning. Personalized learning and teaching can be regarded as the ultimate level of the instruction. Elearning process can be influenced by cognitive and affective factors. Among the effective factor are emotion, personality and individual differences, which can be an effective parameter on human activities such as learning.
People with different personalities show different emotions in the face of an event. The differences in individual characteristics are reflected in their daily activities and their works. In the case of teaching and learning, personality differences among learners play an important role. Personality learners will determine the level of effectiveness in learning style.

An experiment conducted by Seto Mulyadi (2011) through the learning process approach in E-Learning centered on the development of personality, show that to produce graduates with intellectual talents were very good and creative personality can only be achieved if the learning is done with a process approach in the E-learning program. The relationship between cognitive style, personality, and perception of quality multimedia users explored by Stephen R. Gulliver, et al (2010) of the Informatics Research Center, UK, through experiments on cognitive style and personality. They showed that the type of personality and cognitive style affect user information assimilation.

\section{Research Methodology}

Based on the selection of correlational research method used in this study, the researchers focused his efforts on achieving information that can explain the complex phenomena through the relationship between variables. Thus, researchers can also conduct exploratory study via partial correlation techniques, where researchers eliminate one of the variables that influence can be seen the relationship between two variables that are considered important so that it can be seen a variety of variables which are estimated to have a significant role in achieving the learning process. The reasons for the researchers chose to use the correlation study are as follows:

1. There is a need for information that there is a relationship between the variables for the achievement of the correlation coefficient.

2. There is a need to measure several variables and relationships that exist in a realistic setting.

3. The need for researchers to achieve a prediction formula, which is the state that shows the relationship between variables assumptions.

Participants in this study are students who take courses in HCI. The number of students programmed the HCI courses in one semester as many as 344 students. Each student data field has the desired user interface design including background color, font type, font color, shortcut type, feedback type and simple error handling, obtained from questionnaire results. This study aims to determine the effect of personality on the performance of learning with e-learning, especially to know the difference between traditional e-learning and e-learning adaptation in terms of the MBTI personality types, especially extraversion vs. introvert, based on the assessment process performed by a psychologist

The algorithm used in this case study is the Apriori algorithm (Hongyan, et al., 2009). The rules of apriori algorithm consist of two parameters, support (support value) which is the percentage of the combination of those items in the database and confidence (value certainty) that 
the strong relationship between items. This analysis aims to determine all associative rules that meet the minimum support and minimum confidence.

\section{Results and Discussion}

The first step is to load a combination of 1 itemsets at each criteria and frequency of each feature support calculated according to the data in the table of personality types of participants in the database.

The results of the calculation process and the formation of frequent itemset for introvert and extrovert personality types using the minimum support value of $25 \%$ and a minimum of $75 \%$ confident, with the dataset used as training data as much as 223 datasets, will result in the formation of frequent itemset as follows:

a. Introverted Personality Types

$\{$ Blue, Green 1$\}=4$

$\{$ Arial, Green 1$\}=5$

$\{$ Blue, Arial, Black $\}=10$

$\{$ Blue, Arial, Red $\}=5$

\{Blue, Black, Calibri $\}=5$

$\{$ Blue, Black, Times New Roman\} $=36$

$\{$ Blue, Times New Roman, Red $\}=15$

\{Blue, Times New Roman, White $=8$

$\{$ Arial, Black, Red $\}=9$

$\{$ Arial, Black, White $\}=8$

$\{$ Black, Calibri, Green 1$\}=7$

$\{$ Black, Calibri, White $\}=4$

$\{$ Black, Times New Roman, Green 1$\}=6$

$\{$ Black, Times New Roman, Red $=11$

$\{$ Black, Times New Roman, White $=13$

$\{$ Times New Roman, Green 1, Red $=4$

b. Extrovert Personality Type

$\{$ Arial, Black $\}=4$

$\{$ Black, Green 1$\}=3$

$\{$ Black, Calibri $\}=3$

$\{$ Black, White $\}=5$

$\{$ Times New Roman, Green 1$\}=3$

$\{$ Times New Roman, Red $\}=3$

$\{$ Blue, Black, Times New Roman\} $=3$

Based on the outcomes obtained from the training process above, can be explained as follows:

1. In the introverted personality types, the order of the largest combination favored by this type is Blue, Black, Times New Roman\} with a value of 36 datasets, the next combination is B Black, Times New Roman, White $\}$ with a value of 13 datasets. This personality type like Times New Roman font, Calibri, and Arial. While the preferred colors are blue, black, green one, red dan white.

2. In the extroverted personality types, the order of the largest combination favored by this type is \{Blue, Black, Times New Roman $\}$ with a value of 5 datasets, the next combination is $\{$ Arial, Black\} with a value of 4 datasets. The above results indicate that this type is not a too complex combination of variables used in designing e-learning applications, compared introverted type who tend to be more complex combinations. The type of font types like this personality type is Times New Roman and Arial. While the colors are preferably the same as the introverted personality types: white black, green and red one.

While the results of the calculation process and the formation of frequent itemset for introvert and extrovert personality types using the minimum support value of $25 \%$ and a minimum of $75 \%$ confident, with the data set used as the test data as much as 121 datasets, will result in the formation of frequent itemset as follows:

a. Introverted Personality Types

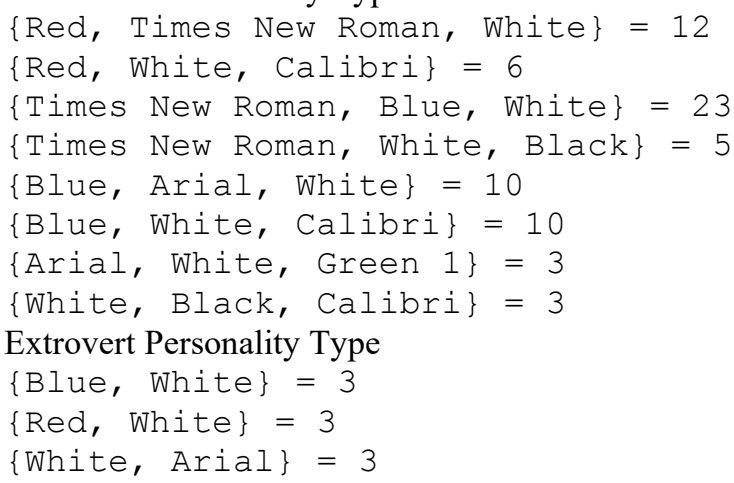

The outcome of the application for the establishment of an association rule introvert and extrovert personality types with datasets that are used as training data as much as 223 datasets, can be seen below:

a. Association Rule Type Introvert

Calibri $=>$ Black $=80.95 \%$

Blue, Red $=>$ Times New Roman $=75 \%$

Arial, White $=>$ Black $=80 \% \mathrm{x}$

Calibri, Green $1=>$ Black $=87.5 \%$

Green 1, Red $=>$ Times New Roman $=80 \%$

b. Association Rule Type Extrovert

Arial $=>$ Black $=80 \%$

White $=>$ Black $=100 \%$

Blue, $\mathrm{Black}=>$ Times New Roman $=75 \%$

While the results of the process of formation of the association rules introvert and extrovert personality types using the minimum support value of $25 \%$ and a minimum of $75 \%$ confident, with the data set used as the test data as much as 121 datasets, will result in the formation of frequent itemset as follows:

a. Association Rule Type Introvert

Times New Roman $=>$ White $=91.3 \%$

Red, Times New Roman $=>$ White $=75 \%$

Calibri $=>$ White $=95 \%$

Red, Calibri => White $=100 \%$

Blue $=>$ White $=97.73 \%$

Times New Roman, Blue $=>$ White $=100 \%$

Black $=>$ White $=100 \%$

Times New Roman, Black $=>$ White = $100 \%$

Arial $=>$ White $=100 \%$

Blue, Arial $\Rightarrow$ White $=100 \%$

Blue, Calibri $=>$ White $=90.91 \%$

Green $1 \Rightarrow$ White $=100 \%$

Arial, Green $1 \Rightarrow$ White $=100 \%$

Black, Calibri $=>$ White $=100 \%$

b. Association Rule Type Extrovert

Blue $=>$ White $=75 \%$

Red $=>$ White $=75 \%$

Arial $=>$ White $=100 \%$ 


\section{Conclusion}

The use of Association rule with a priori algorithm can provide good results in determining combination parameters of the interface in e-learning applications in accordance with the user's personality with the number of participants for the training dataset 223 and 121 participants for the testing, the execution time below 1 second. Based on the results obtained during the training and testing, it can be concluded that the difference in the number of processed dataset affects the association rule frequent itemset formed or produced. For the introverted personality types, examination results between the training dataset and testing dataset shows that there are two combinations that come from these two processes during frequent itemset counting, namely: \{Times New Roman, Blue, White and \{White, Black, Calibri\}, so that it can be said that combination will be selected by the personality of this type. On extrovert personality type, no combination is favored by dominant for this type, and the result is identical to the process of training data. While preferred colors preferred by this personality are blue and white which can be selected as foreground or background colors. Both of these colors appear in the results of the process of training and testing dataset, while the selected font is Arial. Establishment of association rule during the process of training and testing, for the introverted personality types, can be concluded that, if the user selects the Arial font and Calibri, then the foreground color selected is White with a value of $100 \%$ confident. These results also emerge from the process of additional training data with background color options Black. For the extroverted personality types, there are differences in the results of formation of association rule during the process of training and testing.

\section{References}

1. Arockiam, L. \& Selvaraj, J. C., 2013. User Interface Design for Effective E-Learning based on Personality Traits. International Journal of Computer Applications, 61(14), pp. 28-32.

2. Fatahi, S., Kazemifard, M. \& Ghasem-Aghaee, N., 2009. Design and Implementation of an E-Learning Model by Considering Learner's Personality and Emotions. In: Advances in Electrical Engineering and Computational Science. s.1.:Springer Science And Business Media B.V., p. 423.

3. Harman, K. \& Koohang, A., 2007. Learning Objects: Standards, Metadata, Repositories, and LCMS. s.1.:Informing Science.

4. Hongyan, L., Zhong, W. \& Cheng, L., 2009. The Air Cargo Strategy Based on Apriori and ID3. Beijing, s.n.

5. Hung, D., 2001. Theories of learning and computermediated instructional technologies. s.l.:Education Media International.

6. Hung, D. \& Nichani, M., 2001. Constructivism and elearning: Balancing between the individual and social levels of cognition. s.1.:Educational Technology.

7. Perraton, H., 1981. A Theory For Distance Education. s.1.:Prospects. 